\title{
WU DAOZI: SCHILDER VAN GODEN, GOD VAN SCHILDERS
}

Wu Daozi (ca. 689-759) is China's meest beroemde schilder. Zijn roem is echter hoofdzakelijk gebaseerd op overgeleverde literaire verhandelingen van Chinese kunstcritici en niet zozeer op overgeleverd werk. Het meeste van zijn werk was waarschijnlijk al tijdens zijn leven vernietigd.

Willen we echter weten hoe een "Wu Daozi" er uit gezien zou moeten hebben, dan belanden we in een vicieuze cirkel, omdat alle bekende schilderijen toegeschreven aan hem geauthentiseerd werden op basis van van dezelfde literaire verhandelingen. Het fenomeen Wu Daozi begint duidelijk mytholo. gische proporties aan te nemen, maar dat wil niet zeggen dat zijn schilderijen en verhalen dan ook geen waarheidsgehalte voor de kunstgeschiedenis meer hebben. In plaats van de beschrijvingen voor waar aan te nemen, wil ik juìst voorstellen om ze als mythes te behandelen; mythen vertellen namelijk vaak meer over hun makers en de periode waarin zij leefden dan over de legendarische figuren die ze beschrijven. Op deze manier is het mogelijk een paar bekende aan Wu Daozi toegeschreven schilderijen duidelijker te plaatsen in de Chinese kunstgeschiedenis.

Ik zal dit doen door eerst vier schilderijen te behandelen die algemeen verondersteld worden het beste de stijl van Wu Daozi weer te geven' en daarna verder in te gaan op de "mythologie" van de Chinese kunstkritiek met betrekking tot Wu Daozi.

\section{Schilderijen}

De vier afbeeldingen die in dit artikel ter discussie staan, zijn geen schilderijen in de letterlijke zin van het woord, het zijn rubbings. Al vroeg lieten Chinezen teksten of afbeeldingen in stenen stèles graveren zodat er afdrukken van gemaakt konden worden door eerst een papier tegen het stèleoppervlak en in de gravuurlijnen te plakken en daarna met een handzak doorweekt met inkt het oppervlak zwart te maken. De tekst, of afbeelding, verscheen dan in witte lijnvoering tegen een zwarte achtergrond op het papier. De gravuurlijnen zijn vaak een secure weergave van het model. Een goed uitgevoerde rubbing kon zelf ook weer als model voor een stèlegravure worden gebruikt zonder veel aan authenticiteit in te boeten. Dit proces van rubbing naar rubbing stond aan de basis van onze eerste afbeelding die is toegeschreven aan Wu Daozi, de bodhisattva Guanyin.

\section{-1. Guanyin}

Het bekendste Wu Daozi schilderij, in China en in het Westen, is dat van de bodhisattva Guanyin (herkenbaar aan het Amitabha-figuurtje in haar hoofdtooi) afgebeeld met zeer karakteristieke meanderlijnen die de plooien van haar gewaad aangeven en sterk contrasteren met de fijne lijntjes van het gezicht, haar, sieraden, handen en voeten (afbeq). Een paar champigno $n^{0}: 46: 01 \mathrm{Am}$ 

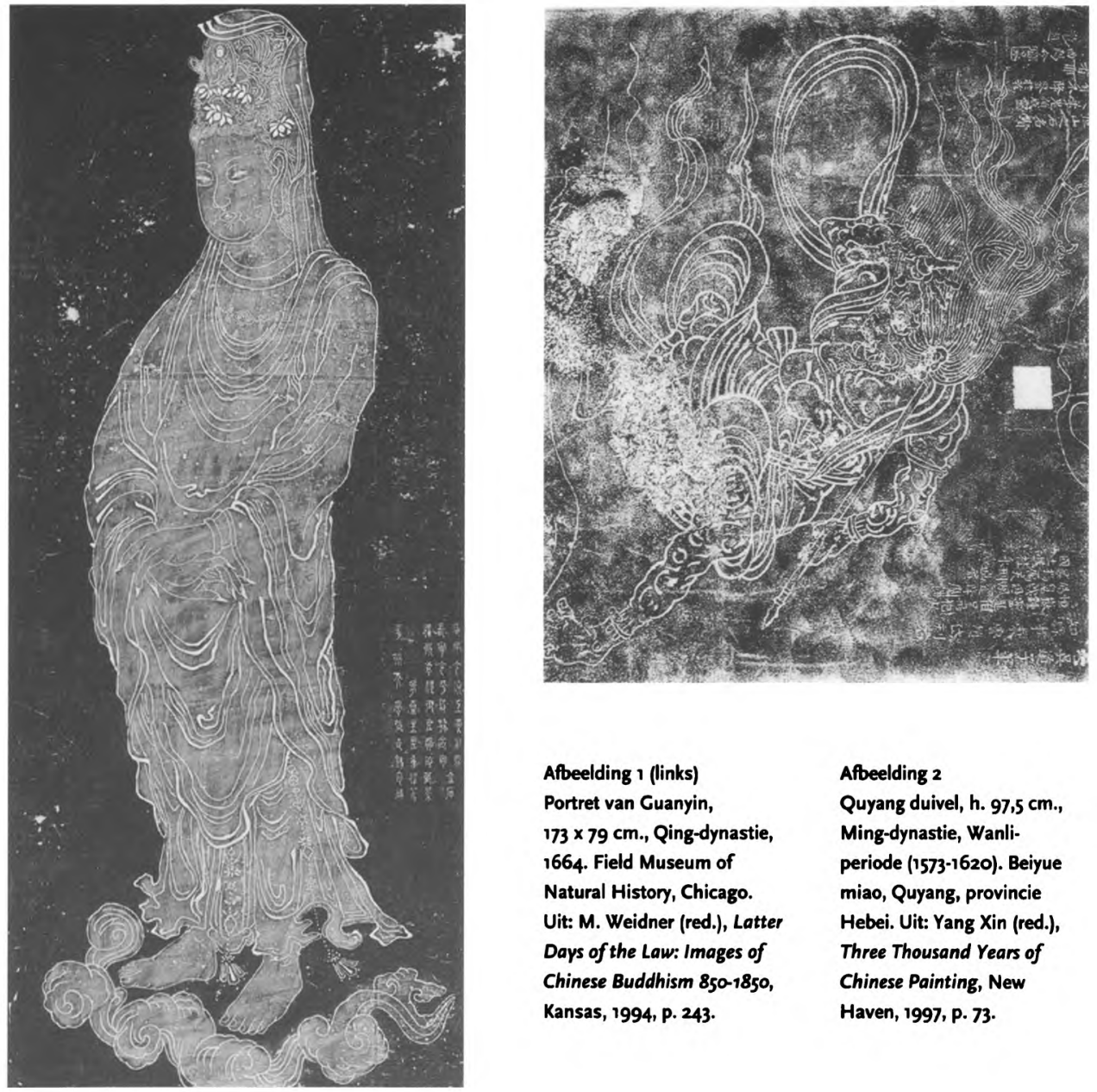

\author{
Afbeelding 1 (links) \\ Portret van Cuanyin, \\ $173 \times 79$ cm., Qing-dynastie, \\ 1664. Field Museum of \\ Natural History, Chicago. \\ Uit: M. Weidner (red.), Latter \\ Days of the Law: Images of \\ Chinese Buddhism 850-1850, \\ Kansas, 1994, p. 243.
}

\begin{abstract}
Afbeelding 2
Quyang duivel, h. $97,5 \mathrm{~cm}$., Ming-dynastie, Wanliperiode (1573-1620). Beiyue miao, Quyang, provincie Hebei. Uit: Yang Xin (red.), Three Thousand Years of Chinese Painting, New Haven, 1997, p. 73.
\end{abstract}

wolkjes, genoemd naar de vorm van de magische lingzhi-zwam, geven aan dat Guanyin in de lucht zweeft, als een teken van haar goddelijke karakter. De stèle-gravure van deze rubbing is gemaakt in 1664, volgens overlevering naar een schilderij door Wu Daozi. Dezelfde gravure kan op tientallen plaatsen in heel China teruggevonden worden, telkens met andere begeleidende teksten, maar met exact dezelfde beeltenis, getuigend van de mobiliteit van het medium rubbing.

Wat maakt deze afbeelding nu typisch Wu Daozi; de gravure is nota bene in 1664 gemaakt? Toch geloofde een groot deel van kunstminnend China dat deze afbeelding daadwerkelijk het meest getrouw de stijl van Wu Daozi weergeeft. Schijnbaar wisten de mensen waar ze op moesten letten. In De geschiedenis van schilderkunst (Huashi) van de Song-connaisseur en kunstcriticus Mi Fu (1052-1107), dat het model vormde waarop latere connaisseurs zich zouden baseren, evalueert hij twee rolschilderingen die hij als authentiek beschouwt met de beschrijving "pulserend en duizelend" en "gemoduleerd en hobbelig", typeringen van Wu Daozi's lijnvoering die evengoed op onze Guanyin afbeelding zouden kunnen slaan. ${ }^{2}$

Het is natuurlijk belangrijk om niet alleen naar de zogenaamde stijl van een schilder te kijken voor het beoordelen van de echtheid, maar ook of er

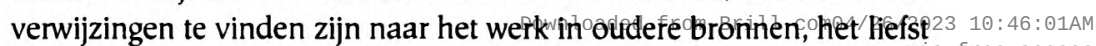


contemporain aan Wu Daozi's periode. In het geval van de Guanyin afbeelding heeft een westerse studie uitgezocht dat de rubbing gebaseerd is op een schilderij uit de Ming-dynastie (1368-1644) dat weer gebaseerd zou zijn op een rubbing van een stèle-gravure uit de elfde eeuw, dat op haar beurt weer was gebaseerd op een authentiek schilderij van Wu Daozi dat in de grootste boeddhistische tempel, de Xiangguo si zou zijn bewaard. ${ }^{3}$ Deze tempel had inderdaad een schilderij van Wu Daozi in bezit, authentiek of niet, maar het was helaas geen Guanyin afbeelding maar een schilderij van Mansjusri in debat met Vimalakirti. ${ }^{4}$

\section{- 2. Demon}

Dit schilderij van een krijger-demon is ook algemeen geaccepteerd als een representatief werk van de stijl van Wu Daozi (afb. 2 ). Het verschil met de Guanyin-afbeelding kan niet groter zijn! De Guanyin straalt een serene rust uit en deze demon lijkt wel een orkaan zelve met zijn woest wapperende haren, kleren die in de wind deinen en spierbundels die over zijn hele lichaam lijken te welven. De meanderlijnen hebben plaatsgemaakt voor strakke, langgerekte strepen, zoals in zijn haren en kledingplooien, terwijl korte, ronde streepjes de spierbundels markeren. De demon lijkt in volle vlucht en met een hand boven zijn ogen tuurt hij zoekend naar beneden, zijn lans in de aanslag voor een aanval.

Hoe valt dit verschil te verklaren? Dit schilderij representeert een andere traditie, of liever, exegese over Wu Daozi. Wu Daozi is voornamelijk beroemd om zijn zeer dynamische stijl, zoals vereeuwigd in het axioma van een Noordelijke Song-kunstcriticus: "Wu's sjerpen dansen in de wind, Cao's gewaden rijzen uit het water." ${ }^{5}$ Wu Daozi representeert een dynamische, Cao Zhongda een statische stijl. Kennelijk werd in de Noordelijke Song (voordat Mi Fu ten tonele verscheen) Wu Daozi geassocieerd met dynamische figuren en een krachtige penseelvoering. De Noordelijke Song-schilder die beide stijlen perfect beheerste en als opvolger van Wu Daozi gold, was Wu Zongyuan (gest. 1050). Mi Fu was zijn grootste criticus en betichtte hem ervan dat "hij dezelfde penseelvoering gebruikte voor zijn rolschilderingen op zijde als voor zijn muurschilderingen en elke streep lijkt dus alsof hij met een mes gesneden is" (d.w.z. ongemoduleerd). ${ }^{6}$ Zo weten we dus dat deze "harde" stijl heel populair was in de vroege Noordelijke Song (960-1127) en met name gebruikt werd voor religieuze figuren in muurschilderingen.

Het thema van een angstaanjagende demon heeft ook duidelijke Wu Daoziconnotaties voor de gemiddeld onderlegde Chinees in de oudheid. Een vroege tekst met een lemma over Wu Daozi, de Optekeningen van beroemde schilders van de Tang dynastie, geeft een anekdote waarin Wu Daozi een aantal hellescènes schildert in een boeddhistische tempel (overigens de eerste verwijzing naar dit later zeer populaire onderwerp) die zo angstaanjagend en levensecht waren dat "alle slagers en vishandelaren terstond van beroep veranderden" (uit angst voor slecht karma dat ze in de hel zou doen belanden). ${ }^{7}$ Menig rolschildering met hetzelfde onderwerp en toegeschreven aan Wu Daozi is terug te vinden in beschrijvingen van collecties van kunstverzamelaars van de Song- tot de Ming-dynastie. Wu Daozi als een schilder van demonen genoot een grote populariteit.

Dit mag dan ook als reden verondersteld worden waarom exact dit figuur uit een hele muur vol schilderingen is uitgekozen om de stijl van Wu Daozi te representeren. Namelijk, de stèle-gravure is een kleinschalige kopie van een demon uit de tempelmuurschilderingen vande Beiyue milao (Tempel $20 a n$ de $46: 01 \mathrm{AM}$ 
Noordelijke Heilige Piek) in Quyang, provincie Hebei, waar hij nog steeds bezichtigd kan worden en waar ook de stèle-gravure te vinden is. De muurschilderingen stellen een audiëntie van keizergoden en hovelingen in een hemelhof in een berglandschap voor en de hele compositie bezit een uitzonderlijke dynamische kwaliteit die elk haartje en vaantje van de compositie in beweging zet.

Zijn deze muurschilderingen dan van Wu Daozi? Dat lijkt bijna onmogelijk. Ook al schrijft de districtsgeschiedenis van Quyang uit de Ming dit wel, de tempel is volledig verwoest geraakt in de tiende eeuw en waarschijnlijk nogmaals in de vroege dertiende eeuw, beide tijdens oorlogen. De tempel, althans het dak, is herbouwd in 1270 en de muurschilderingen zullen rond deze tijd aangebracht moeten zijn, maar een vroege Song-datum zou ook mogelijk kunnen zijn, juist omdat de dynamische stijl van Wu Daozi zo populair was in die periode; de muurschilderingen zijn totaal anders dan andere voorbeelden uit de dertiende of veertiende eeuw. ${ }^{8}$

De stèle met de vliegende demon, in de volksmond de "Quyang duivel" geheten, is overigens pas in de Wanli-periode (1573-1620) van de Ming gegraveerd. Het is waarschijnlijk niet zonder reden om plotseling zoveel eeuwen nadat de muurschilderingen zijn aangebracht een propagandaoffensief te beginnen met een Wu Daozi schilderij. Wu Daozi genoot zeker een grote faam in de late Ming, maar hier speelt nog een andere reden.

De Beiyue miao is een staatstempel waar rituelen voor de Noordelijke Heilige Piek werden gehouden. De tempel lag in de buurt van deze berg. Maar in 1568 verordonneerde het Ming-hof dat met de "Noordelijke Heilige Piek" een andere berg werd aangeduid, veel verder naar het noorden gelegen.

De beheerders van de tempels, en zeker de lokale bevolking en middenstand, hadden de bui al zien hangen en vreesden dat de tempel ook verplaatst zou worden en hadden in 1547 al een plattegrond en een lijst van alle bezittingen van de tempel in een stèle laten graveren, om het belang van de tempel te onderstrepen. Enkele decennia later volgde nog de gravure met de Wu Daozi demon, maar het mocht niet baten. In 1660 werden de rituelen, samen met de inkomsten, officieel naar een nieuwe tempel verplaatst.

\section{- 3. Confucius}

De beeltenis van Confucius ( $\mathrm{afb} .3$ ) is weer een heel ander verhaal. Net als bij de Guanyin-afbeelding, is hiervan dezelfde stèle-gravure te vinden op verschillende plaatsen in China. Deze staat in Qufu, provincie Shandong, de plaats waar de officiële Confucius-tempel staat en waar ook de zoveelste nazaat van de grote meester nog woont.

Qua stijl worden we opnieuw geconfronteerd met een volledig nieuwe benadering. De langgerekte lijnen die de plooien en contouren van Confucius' gewaad aangeven, zijn licht gemoduleerd maar in feite weinig verheffend, terwijl fijne lijntjes gebruikt worden voor zijn gezichtsbeharing en de versierde randen van zijn kleed, ook zonder al te veel fantasie. De driekwart pose die Confucius aanneemt met handen samengevoegd in verering en de indeling van zijn gewaad doen echter sterk denken aan de standaardmethoden om daoïstische goden af te beelden; alleen het hoofd lijkt te zijn verwisseld met dat van een oude man.

De geschiedenis van de rubbing is tevens onduidelijk. Er zou een dergelijke stèle-gravure gemaakt zijn van Confucius in $1095,{ }^{9}$ maar dan is dit een ver verdwaalde kopie van het origineel, niet alleen vanwege het matige penseelwerk, maar ook omdat de titel walurmee Confucius wordt gee via $^{3}$ 

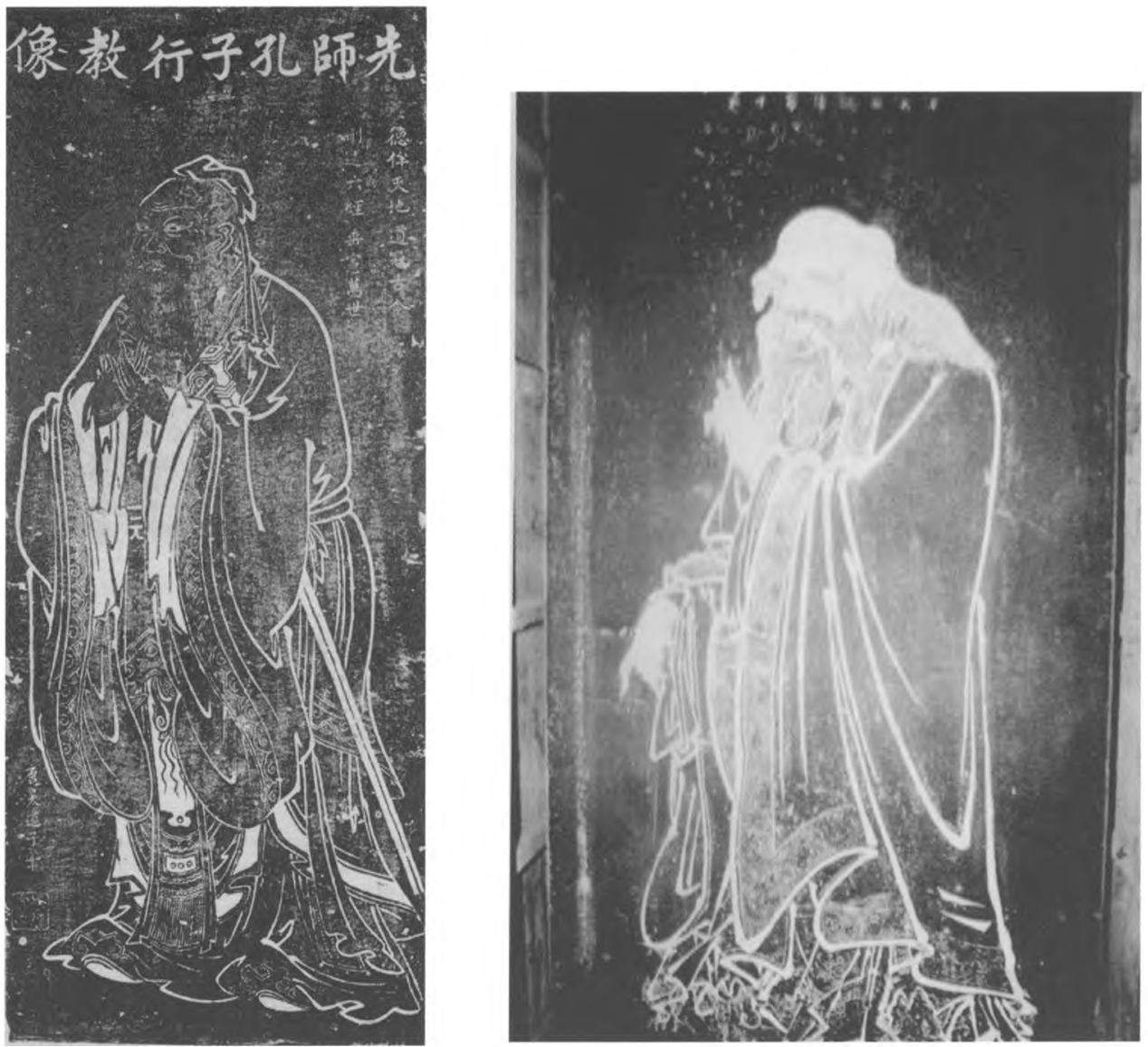

Afbeelding 3

Portret van Confucius, Ming-dynastie (1368-

1644), na 1530. Uit:

Huang Miaozi, Wu

Daozi shiji (Verzamelde

feiten over Wu Daozi),

Beijing, 1991.

\section{Afbeelding 4}

Portret van Laozi, Zui-

delijke Song-dynastie,

1225. Xuanmiao guan,

Suzhou, provincie

Jiangsu. Uit: Zhu Yueli

(red.), Zhongguo

daojiao gongguan

wenhua (Daoistische

tempelcultuur in China),

Beijing, 1996. bovenaan de stèle, "Eerste meester," uit de Ming stamt, uit 1530 om precies te zijn. Men kan zich afvragen waarom zo'n schilderij van Confucius aan Wu Daozi wordt toegeschreven. Waarschijnlijk omdat er ook eentje bestond van Laozi, de andere Chinese wijsgeer uit de klassieke oudheid.

\section{- 4. Laozi}

Met de afbeelding van Laozi belanden we plotseling op heel ander terrein (afb. 4). Dit werk is nog nooit bestudeerd in enige studie ${ }^{10}$ en naar mijn weten ook nog nooit buiten China gepubliceerd. Het staat ook in geen enkele oude verhandeling van een Chinese kunstcriticus vermeld. Alleen op Chinese toeristische en daoïstische websites wordt deze afbeelding tegenwoordig vermeld. De stèle-gravure is te vinden in de Xuanmiao guan te Suzhou en geeft op een vrij aparte manier een beeltenis van de oude meester. Ook deze lijnen zijn licht gemoduleerd maar niet zo heftig als bij de Guanyin-afbeelding en stralen een grote daadkracht uit, te meer omdat de lijnen in het "open" gebied van de rug en arm vrij breed en vet zijn en in het "gesloten" gebied onder, boven en links een fijnzinnigere benadering aannemen. Een andere aparte methode is dat het kale hoofd en gezicht als ook de handen volledig blank gelaten zijn (dus concaaf), wat er voor zorgt dat zowel de stèle-gravure als de rubbing op deze plekken helder wit zijn en dus sterke nadruk krijgen naast de lijnvoering. Artisticiteit en religieuze effectiviteit zijn hier perfect met elkaar in harmonie gebracht. 


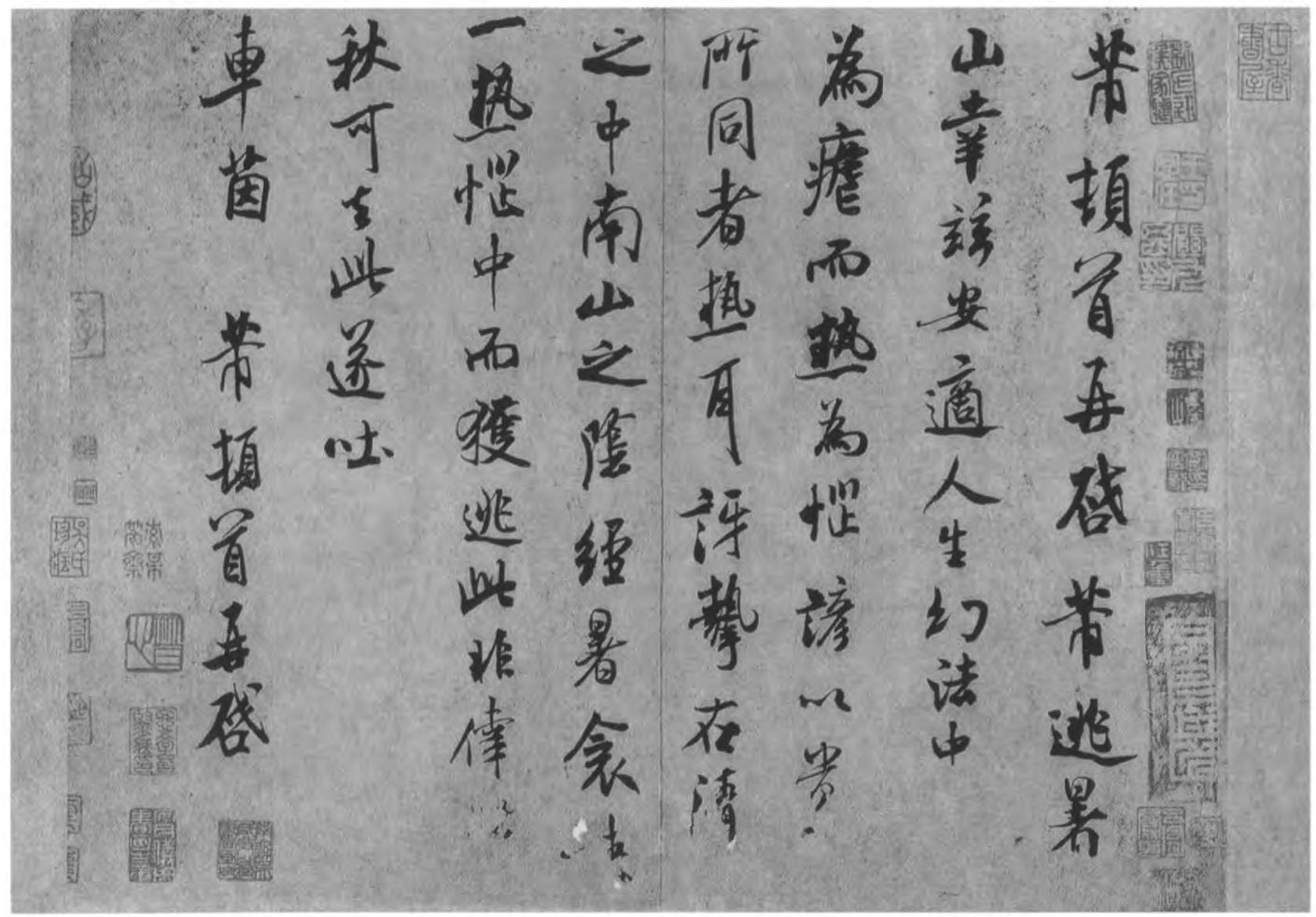

Afbeelding 5 Kalligrafie van Mi Fu (1052-1107),

Ontsnappen aan de zomerhitte, 30,9 × 40,6 cm., 1093. John b. Elliott Collection. Uit: R.E. Harrist Jr. (red.), The Embodied Image. Chinese Calligraphy from the John B. Elliott Collection, Princeton, 1999, p. 112.
Stijltechnisch gezien kan dit werk van een groot schilder geweest zijn. Een saillant detail in de Laozi-figuur, namelijk de scheve verhouding tussen hoofd en de rest van zijn lijf, is voor een keer ook toe te wijzen aan deze grote schilder Wu Daozi. Wu Zongyuan, de Song-schilder heeft, als enige zover ik weet, Wu Daozi bekritiseerd en gezegd dat de nekken van zijn figuren te kort waren. Dat is ook het geval bij de Laozi afbeelding. Het ontbreken van Laozi's nek is de oorzaak van de disproportionele verhoudingen binnen het figuur.

Ondanks de geringe bekendheid van de Laozi-afbeelding, is dit het enige werk, een kopie dat wel, dat met enige zekerheid aan Wu Daozi kan worden gelieerd. We weten bijvoorbeeld dat Wu Daozi inderdaad een schilderij op zijde van Laozi heeft gemaakt; het hing in de centrale staatstempel in Chang'an gewijd aan Laozi, de Taiqing gong. " De geschiedschrijving van de Tang levert de band tussen dit schilderij en de stèle-gravure in Suzhou; de obscuriteit van zo'n vermelding in een niet-kunsthistorische bron is misschien ook de reden waarom deze band altijd onopgemerkt is gebleven. In 741 begon Tang-Keizer Xuanzong (r.712-756) een nationale cultus rond Laozi (Laozi was al een god binnen het daoïsme en was ook ingeschakeld als aartsvader van de keizerlijke familie voor legitimatie doeleinden) nadat hij door Laozi in een droom was bezocht. Om dit moment te herdenken en kenbaar te maken, liet hij meteen een schilder bij zich roepen om een portret van Laozi te maken zoals hij hem in zijn droom had gezien. Kopieën van dit portret

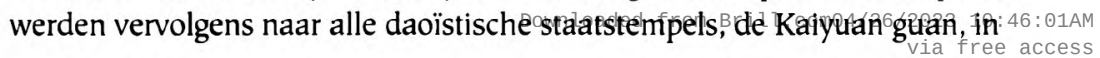


het rijk gestuurd om daar met rituelen te worden geëerd. ${ }^{12}$ De huidige Xuanmiao guan was zo'n Kaiyuan guan in de Tang-periode waar dus een Laozi-portret aanwezig was. Hoewel niet gespecificeerd is wie die schilder was die de keizer bij zich riep, moet dit Wu Daozi geweest zijn, aangezien een Laozi-portret van zijn hand in de belangrijkste tempel van het land hing. Dit portret van Wu Daozi zou dan het prototype zijn geweest voor de kopieën (rubbings?) die over het rijk verspreid zijn. ${ }^{13}$

De huidige stèle-gravure is gemaakt in 1225 na herstelwerkzaamheden aan de tempel. De oude stèle zou zijn gebroken en op basis daarvan is dus een nieuwe gegraveerd. Naast de beeltenis van Laozi bevat de stèle ook een lofdicht gemaakt door Keizer Xuanzong, gekalligrafeerd door de beroemdste kalligraaf van de Tang en ook staatsman en daö̈stisch meester, Yan Zhenqing (709-785), wat de stèle tot een kleine kunstschat zou maken als alle claims waar zouden kunnen zijn. Het blijft natuurlijk de vraag of de Song-versie dezelfde is als het Tang-origineel.

\section{Chinese kunstkritiek als mythologie}

Wu Daozi was een schilder van hoofdzakelijk godenfiguren en hij was daar zo goed in dat hij al kort na zijn dood goddelijk werd verklaard. Gedurende de hele keizerlijke periode daarna is Wu Daozi ook werkelijk als god of als patroonheilige van het schildersgilde vereerd.

Wie Wu Daozi, de persoon, precies is geweest, is moeilijk vast te stellen en een biografie over zijn leven schrijven is vrijwel onmogelijk. Het feit dat hij is vergoddelijkt, maakt het echter mogelijk om een soort kunstmythologie over hem te schrijven, waarbij de meningen van de kunstcritici over Wu Daozi's schilderstijl niet als "waar" moeten worden gezien, maar liever als indirecte toespelingen van de auteurs zelf, over wat zij in kunst en schilderstijl belangrijk vinden. De discussie over de voorgaande vier schilderijen kunnen goed als uitgangspunt dienen voor onze kunstmythologie van Wu Daozi. Wat we bijna met zekerheid weten is dat Wu Daozi een muurschilderaar was; hij zou volgens een betrouwbare contemporaine bron meer dan driehonderd schilderingen hebben gemaakt in boeddhistische en daoïstische tempels in de twee Tang hoofdsteden, Chang'an (tegenwoordig Xi'an) en Luoyang. Wat ook met vrij grote zekerheid te zeggen is, is dat bijna niet één muurschildering de volgende eeuw heeft overleefd, anders dan wat er misschien door andere of latere schilders is gekopieerd. Tijdens zijn leven al, in 756, werden de twee hoofdsteden volledig verwoest en moest het Tang-hof en ook Wu Daozi vluchten naar Sichuan (waar dus ook een Wu Daozitraditie opbloeide) in Zuidwest-China. Honderd jaar later, in 845, zorgden boeddhistische vervolgingen ervoor dat verder alle boeddhistische kloosters verwoest dan wel ontmanteld werden. Wat er misschien nog restte van Wu Daozi's werk was nu voorgoed verloren gegaan.

De vroegste twee kunstcritici die het werk van Wu Daozi beschrijven stammen uit 840 , dus net voor de vervolgingen, en uit 847 , net na de verwoestingen. Typerend voor beide werken is dat ze geen van beide precieze beschrijvingen geven van schilderijen van Wu Daozi die ze hebben gezien of van zijn penseelvoering (de tweede geeft wel een lijst van tempels met onderwerpen die Wu Daozi daar geschilderd zou hebben, maar het is onduidelijk of hij die vanuit zijn geheugen noemt of dat de schilderijen er destijds nog waren). Beiden putten zich ook uit om de goddelijkheid van zijn kunst aan te tonen. Laten we hier dus onze kunstmythologie begintnenfrom Brill.come4/26/2023 10:46:01AM 
De vroegste tekst, de Optekeningen van beroemde schilders van de Tangdynastie van Zhu Jingxuan (ca. 840), geeft een aantal korte anekdoten, waarvan sommige duidelijk apocrief zijn: een zwaarddans van een beroemde generaal die Wu Daozi inspireerde om in een dynamische stijl te schilderen (hetzelfde verhaal overigens wordt ook wel aangevoerd om te vertellen hoe een beroemde kalligraaf, Zhang Xu, geïnspireerd raakte); vanuit het geheugen en zonder schetsboek bergketens naschilderen en onderwijl een vermaarde landschapsschilder (die al bijna een eeuw dood was) verslaan in snelschilderen; levensechte draken schilderen die regen brengen; perfect ronde halo's schilderen zonder passer te hoeven gebruiken; en natuurlijk de eerder genoemde helschilderingen die slagers en vissers van vak deden veranderen. ${ }^{14}$ Het magische element prevaleert in deze optekeningen.

De andere tekst, de Notities over beroemde schilders door de eeuwen heen van Zhang Yanyuan (ca. 815-875), noemt als eerste Wu Daozi een "god van schilders" en na een obscure beschrijving van zijn goddelijke stijl, introduceert hij een ware kunstfilosofie die hij dus aan Wu Daozi toedicht: "Door zijn geest te bewaren en zich te concentreren op zijn eenheid, wist hij zich te versmelten met al het werk van creatie en transformatie. In deze toestand (van harmonie) werd zijn penseel als het ware geleend zodat, zoals het heet, "door de intentie te visualiseren (in een schilderij) voordat het penseel in beweging komt, de intentie aanwezig blijft terwijl het schilderij al af is."15 De auteur introduceert hier echter een vorm van kunstkritiek die normaliter was voorbehouden aan kalligrafie; de continuïteit van de penseellijn en de sturing door de geest staan centraal bij kalligrafie. Het gevolg is echter dat met deze nieuwe benadering schilderkunst als een vorm van kalligrafie wordt gezien (Zhang Yanyuan zegt dat ook herhaaldelijk in zijn werk) en dat alle nadruk in de beschouwing van een Chinees schilderij op de penseelvoering komt te liggen en niet zozeer op compositie of kleurgebruik. Zhang Yanyuan is ook de eerste die voortdurend vermeldt dat Wu Daozi zijn eigen werk niet inkleurde maar dat overliet aan "vaklui", die het schilderij dan ook regelmatig verpestten (bij Zhu Jingxuan voegde Wu Daozi zelf nog de kleuren toe).

Dat schilderkunst en kalligrafie eenzelfde kunstvorm zijn en dat schilderkunst het best monochroom in zwarte inkt is, is tot op de dag van vandaag de traditionele mening, in de Chinese kunst. Deze visie begon in de negende eeuw en beide transformaties worden verpersoonlijkt in de figuur van Wu Daozi. In de Noordelijke Song-dynastie (960-1127) vindt er weer een nieuwe transformatie plaats op het gebied van de schilderkunst en weer speelt Wu Daozi daarin een centrale rol. Aan de ene kant is er een groep vakkundige muurschilders aangevoerd door Wu Zongyuan die sterk in de traditie van Wu Daozi werkten (bijna al deze schilders waren afkomstig uit Luoyang waarbuiten nog een tempel was, toevallig ook een Laozi-tempel, waar nog originele schilderijen van Wu Daozi waren tot eind tiende eeuw). De vroege Song-kunstcritici die deze schilders beschrijven zijn nog vol lof over deze schilders en hun stijl wordt gekenmerkt door het dictum dat "Wu Daozi's sjerpen dansen in de wind". Ze hadden waarschijnlijk een heel scherpe, harde penseelvoering, zoals die ook nog te vinden is in latere muurschilderkunst en veel religieuze schilderkunst. Deze lijnvoering wordt later door critici de "ijzerdraad-stijl" genoemd en teruggevoerd op een beroemde maar nog mythologischere schilder Gu Kaizhi (ca. 345-406). Wu Daozi verpersonificeert de nieuwe stijl van lijnvoering die onder schilders en kunstcritici wordt gepromoot aan het einde van de elfde eeuw. Schilderkunstcritici als Mi Fu, maar ook de berbemdeddichter SuiShicbehoren²023 10:46:01AM 


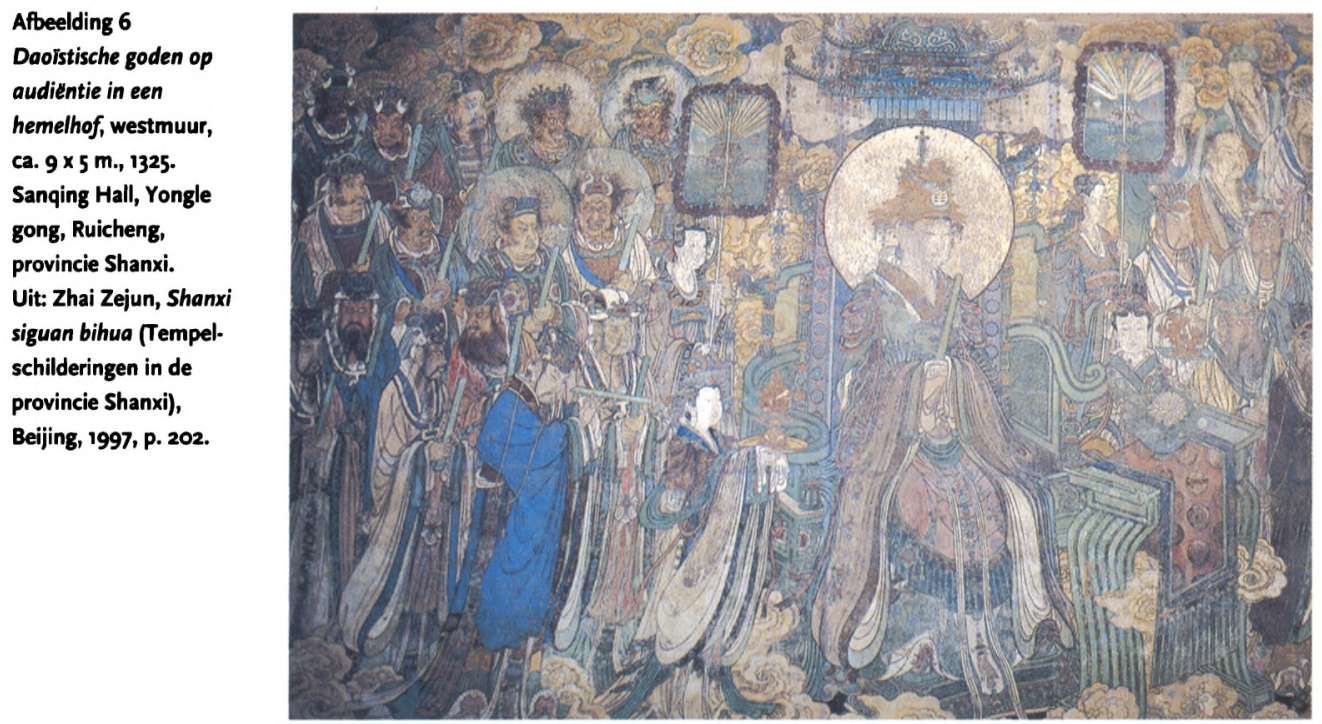

allemaal tot een nieuwe sociale klasse, die we de literati noemen. Zowel wat betreft klasse als kunstopvattingen staan zij lijnrecht tegenover de meer professionele hofschilders en het is hen er erg aan gelegen om zich van deze andere groep te distantiëren. Dit doen ze door in hun kunstkritische verhandelingen hun eigen idealen over kunst uiteen te zetten. Het is daarom niet verwonderlijk dat zij in teksten juist Wu Daozi verkiezen om deze nieuwe opvattingen te verbeelden. Het sterk gemoduleerde penseelwerk is hun norm en we zien dus eenzelfde nadruk op modulatie in hun kalligrafeerwerk. Immers, het waren vooral de literati die het ideaal van eenzelfde oorsprong van schilderkunst en kalligrafie voorstonden. Als hoge ambtenaren in de keizerlijke bureaucratie waren zij bovendien bedreven in kalligrafie en nadruk op penseelvoering in schilderkunst paste mooi bij hun ideaal van "amateur-kunstenaars" en kon hun onkunde in de andere aspecten van de schilderkunst verhullen. De bewust gemoduleerde penseelvoering is bijvoorbeeld goed te zien in een kalligrafie van Mi Fu uit 1093, die sterk afsteekt met het meer vloeiende penseelwerk van kalligrafen uit eerdere periodes (afb. 5). De overgang van vloeiende naar sterk gemoduleerde lijnen wordt dus door kunstcritici uit de literati-kringen toegeschreven aan Wu Daozi en zo wordt Wu Daozi van een god van muurschilders ook ingelijfd als icoon van literati-kunstenaars.

Waarschijnlijk moet deze nieuwe benadering van godenfiguren wrijving hebben opgeleverd met wat algemeen geassocieerd werd met de Wu Daozistijl en wat destijds nog steeds in elke tempelschildering te zien was. We zien juist dat de scherpe lijnvoering alleen maar wordt benadrukt in religieuze muurschilderkunst tot en met de Yuan-dynastie (1279-1368) doordat alle zwarte lijnen na completering nogmaals eens met dik zwart worden aangezet. Deze techniek was nog niet in gebruik in de Tang-dynastie. We zien dus in kunstkritische verhandelingen van de Yuan-periode dat men dit verschil probeert te verklaren, ook weer door WunDaozir dals de boorsprong dáarvoor : : 46: 01AM 
aan te wijzen. Dong Yu (vroege 12e eeuw) schrijft bijvoorbeeld nog dat Wu Daozi's "penseelsporen rond en dun zijn als verdraaid koperdraad," terwijl Tang Hou (vroege 14e eeuw) toevoegt dat hij "in zijn vroege jaren dunne lijnen gebruikte." ${ }^{16}$ Dat Wu Daozi's stijl in een vroege en latere periode kan worden ingedeeld, is volledig nieuw en in de Ming-dynastie (1368-1644) zien we een andere kunstcriticus, Zhang Chou, die een Tangwerk "citeert" waarin zou staan dat Wu Daozi's "penseelmethode veranderde. Op jonge leeftijd schilderde hij lijnen licht en dun, gelijk een lentezijderups die fijne zijde spint. Op middelbare leeftijd schilderde hij lijnen ruimhartig en heldhaftig, even extravagant als een waterlelie." ${ }^{17}$ De auteur lost hier dus een oud probleem op door Wu Daozi in zijn eigen leven de transformatie van recht naar gemoduleerd te laten doormaken. Deze laatste transformatie in de kunstmythologie markeert ook de laatste fase van de ontwikkeling van de literati-kunst; in de Ming-dynastie wordt literati-kunst de uiteindelijke norm voor alle Chinese kunst. ${ }^{18}$

We zien dus dat in verschillende fasen de legendarische schilder Wu Daozi wordt ingelijfd door verscheidene kunstcritici om hun eigen idealen en opvattingen over schilderkunst te verbeelden. Geen van hun oordelen is gebaseerd op een origineel werk van Wu Daozi. De centrale rol die Wu Daozi inneemt in de Chinese kunstgeschiedenis maakt hem bij uitstek geschikt om deze geschiedenis te verwoorden. Door een kunstmythologie over hem te schrijven zijn we helaas niet meer over zijn persoon of zijn werk te weten gekomen, maar hebben we wel een paar belangrijke momenten in de ontwikkeling van de Chinese schilderkunst aan de hand van zijn goddelijke status kunnen ontleden.

Deze ontwikkeling van Wu Daozi's kunstmythologie is ongeveer als volgt. Tot de negende eeuw werd schilderkunst nog het meest in termen van religie of magie gezien en werd weinig aandacht geschonken aan typisch kunstzinnige opvattingen. Dit verandert aan de eind van de negende eeuw wanneer schilderkunst wordt vereenzelvigd met kalligrafie en opvattingen over kalligrafie worden toegepast op schilderkunst, zoals de nadruk op monochroom. Deze opvattingen worden gemeengoed onder literati die aan het eind van de elfde eeuw sterke lijnmodulatie promoten, vooral om zich sociaal en kunstzinnig te kunnen onderscheiden van meer "professionele" schilders, die een veel scherpere lijntechniek voeren. De twee blijven naast elkaar bestaan tot in de Ming-dynastie het onderscheid wordt geslecht in het voordeel van de literati. Literati-kunst is de nieuwe en de enige norm. Wu Daozi symboliseert deze hele ontwikkeling.

En wat zegt deze ontwikkeling over de Laozi-afbeelding? Als we alleen op het penseelwerk letten, valt op dat de lijnvoering licht gemoduleerd is. De vraag is natuurlijk in welke mate. Als we het echter vergelijken met de Guanyinafbeelding of met Mi Fu's kalligrafeerwerk, dan lijken de lijnen in de Laoziafbeelding toch meer bedoeld te zijn om plooiveranderingen in het gewaad aan te geven, in tegenstelling tot de Guanyin of Mi Fu waarbij elke meanderlijn bedoeld is om te meanderen en niets anders. Samen met de geschiedenis van de gravure, en de compositorische kenmerken is de Laozischildering een sterke kandidaat voor een Wu Daozi-voorbeeld. Toch kan men ook hier niet aan de gedachte ontsnappen dat de kopiist in 1225 juist in het lijnwerk liever de mythe dan het origineel heeft willen volgen! 
Acker, William, Some T'ang and Pre-T'ang Texts on Chinese Painting. Vol. 1. Leiden: Brill, 1954

Bush, Susan, The Chinese Literati on Painting: Su Shih (1037-1101) to Tung Ch'ich'ang (1555-1636). Cambridge: Harvard University Press, 1971.

Cefu yuangui gecompileerd door Wang Qinruo (962-1025), j. 53. Beijing: Zhonghua shuju, 1960.

Huang Miaozi, Wu Daozi shiji (Verzamelde feiten over Wu Daozi). Beijing: Zhonghua shuju, 1991.

Huashi (Geschiedenis van schilderkunst) door Mi Fu (1052-1107) in Zhongguo shuhua quanshu, vol. 1. Shanghai: Shanghai shuhua chubanshe, 1993.

Rao Zongyi, "Wuxian Xuanmiao guan shichu huaji" (Schildersporen op steen in de Xuanmiao guan van het $\mathrm{Wu}$ district). Zhongyang yanjiuyuan lishi yuyan yanjiusuo jikan 45.2 (1987), pp. 255-309.

Tangchao minghua lu (Optekeningen van beroemde schilders van de Tang-dynastie) door Zhu Jingxuan (ca. 840), in He Zhiming and Pan Yungao (annotators), Tang Wudai hualun. Changsha: Hunan meishu chubanshe, 1997.

Tuhua jianwen zhi (Kroniek van wat ik zag en hoorde over schilderijen) door Guo Ruoxu (ca. 1080), in Mi Tianshui (annotator), Tuhua jianwen zhi, Hua ji. Changsha: Hunan meishu chubanshe, 2000.

Weidner, Marsha (ed.), Latter Days of the Law: Images of Chinese Buddhism 850-1850. Kansas: Spencer Museum of Art, 1994

\section{Noten}

1. Huang Miaozi, Wu Daozi shiji (Verzamelde feiten over Wu Daozi). Beijing: Zhonghua shuju, 1991, p. 129.

2. Ibid., pp. 141-142

3. Marsha Weidner (ed.), Latter Days of the Law: Images of Chinese Buddhism 8501850. Kansas: Spencer Museum of Art, 1994, p. 244.

4. Tuhua jianwen zhi (Kroniek van wat ik zag en hoorde over schilderijen) door Guo Ruoxu (ca. 1080), in Mi Tianshui (annotator), Tuhua jianwen zhi, Hua ji. Changsha: Hunan meishu chubanshe, 2000, p. 192.

5. Ibid., p. 37. Cao slaat op Cao Zhongda, een schilder actief tijdens de Noordelijke Qidynastie (550-577).

6. Huashi (Geschiedenis van schilderkunst) door Mi Fu (1052-1107) in Zhongguo shuhua quanshu, vol. 1. Shanghai: Shanghai shuhua chubanshe, 1993, p. 981.

7. Tangchao minghua lu (Optekeningen van beroemde schilders van de Tang-dynastie) door Zhu Jingxuan (ca. 840), in He Zhiming and Pan Yungao (annotators), Tang Wudai hualun. Changsha: Hunan meishu chubanshe, 1997, p. 85.

8. Onderzoek naar de architectuur heeft aangetoond dat het dak inderdaad uit Yuandynastie stamt, maar dat de houten pilaren van meer dan tien meter hoog een sokkel in Song-stijl hebben, dus uit de Song stammen en dus niet verwoest zijn, wat zou kunnen betekenen dat de muren van ruim twee meter dik ook de verwoesting overleefd hebben en uit de Song zouden kunnen stammen.

9. Huang Miaozi, Wu Daozi shiji, p. 126.

10. Huang Miaozi noemt het werk maar behandelt het niet omdat hij meent dat het verloren is gegaan. Dit geldt ook voor Rao Zongyi, "Wuxian Xuanmiao guan shichu huaji" (Traces of Painting on Stone Slabs from the Xuanmiao guan in Wu County).

Zhongyang yanjiuyuan lishi yuyan yanjiusuo jikan 45.2 (1987), pp. 273-276.

11. William Acker, Some T'ang and Pre-T'ang Texts on Chinese Painting. Vol. 1. Leiden: Brill, 1954, p. 256.

12. Cefu yuangui gecompileerd door Wang Qinruo (962-1025), j. 53. Beijing: Zhonghua shuju, 1960, pp. 594-595. 
13. Deze verspreiding over het rijk zou vooronderstellen dat er misschien nog meer en precies dezelfde Laozi afbeeldingen te vinden zijn, en er schijnt daadwerkelijk in China nog ergens een stèle-gravure te zijn (volgens internet) maar ik heb niet kunnen achterhalen waar.

14. Tangchao minghua lu, pp. 83-85.

15. William Acker, Some T'ang..., p. 181.

16. Huang Miaozi, Wu Daozi shiji, p. 153.

17. Rao Zongyi, "Wuxian Xuanmiao guan shichu huaji", p. 275. Dit citaat is duidelijk apocrief omdat het werk van Deng Mou voor het laatst in de Song wordt vermeld. Bovendien kan men zich afvragen waarom zulke waardevolle informatie nog nooit eerder is geciteerd door mensen die zeker het werk van Deng Mou tot hun beschikking hadden zoals Zhang Yanyuan en Guo Ruoxu.

18. Susan Bush, The Chinese Literati on Painting: Su Shih (1037-1101) to Tung Ch'ich'ang (1555-1636). Cambridge: Harvard University Press, 1971. 


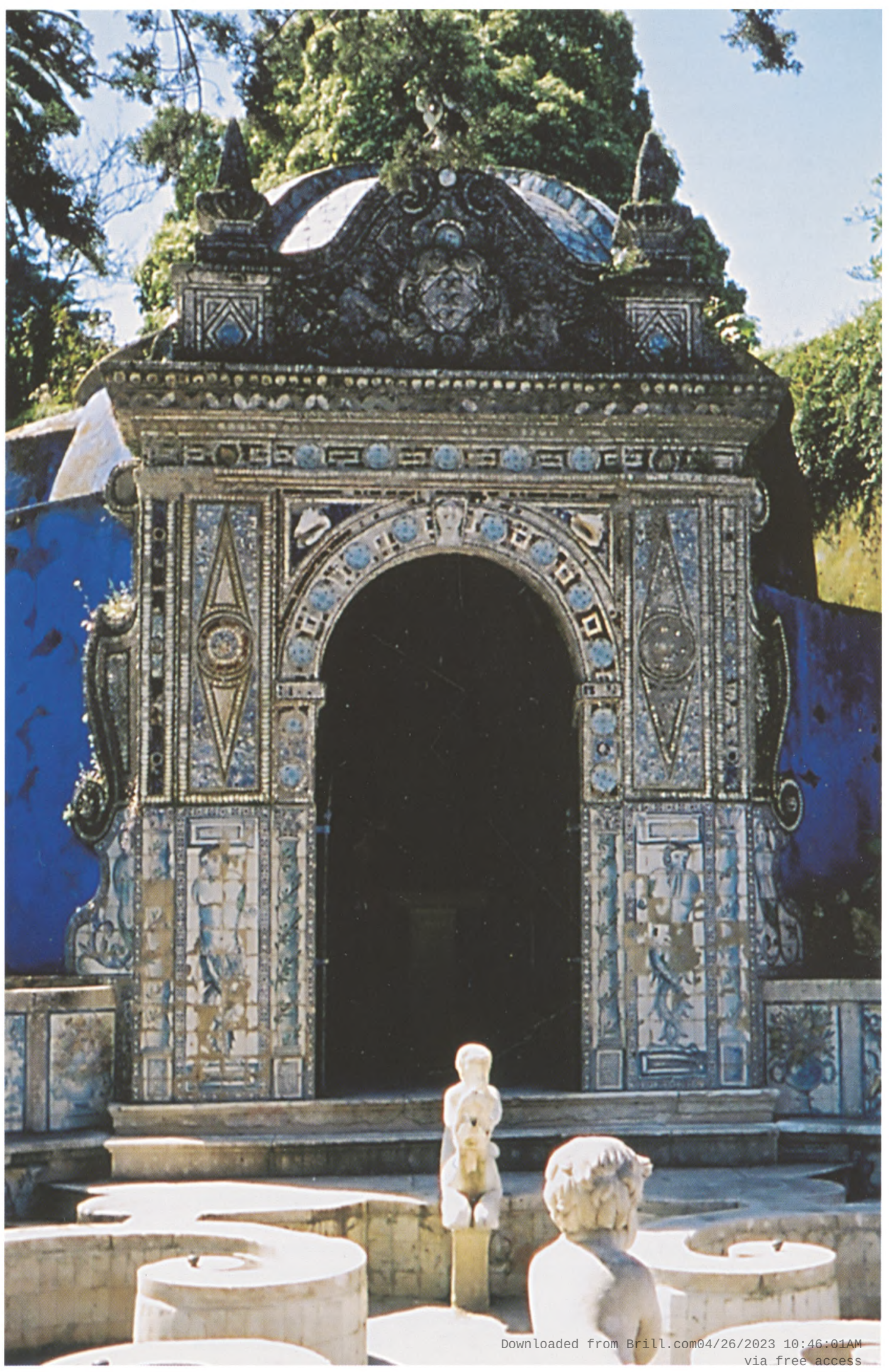

